\title{
Marie Curie takes to the screen
}

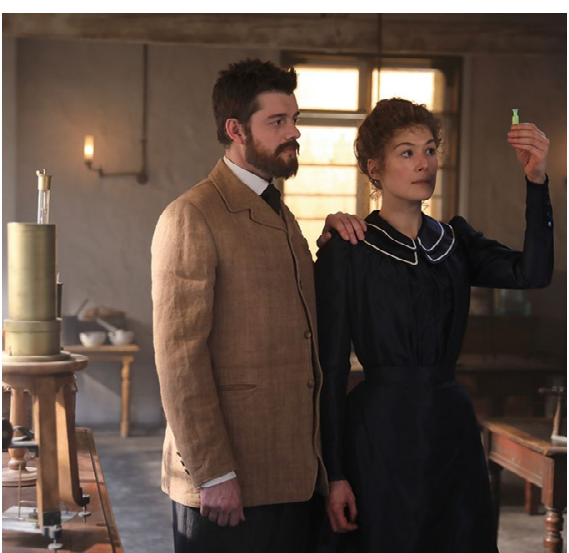

Radioactive

Director: Marjane Satrapi

Shoebox/Working Title/StudioCanal.

ilms about scientists help to humanize - figures sometimes seen as distant, and provide the public with insights into the process and excitement of discovery. At a time when experts and science are often questioned, such films remind viewers of the importance of research, replacing suspicion with curiosity. Radioactive, a new biopic of Marie Curie, manages to do just the opposite.

Directed by Marjane Satrapi and starring Rosamund Pike and Sam Riley, the film takes inspiration from the graphic novel Radioactive: Marie and Pierre Curie, A Tale of Love and Fallout by Lauren Redniss. The release in cinemas, scheduled for March 2020, had to be cancelled owing to the coronavirus pandemic, but the film will be available on Amazon Prime from June 15 and on DVD from July 27.

The story starts in 1934, with Marie being rushed to hospital. As her last moments approach, we are taken to flashbacks from her past. Her mind goes back to her first encounter with Pierre Curie, her future collaborator, husband and co-winner of the Nobel Prize, and their first years together at the end of the 1890s.

A dinner party with a curious (female) friend provides the excuse to summarize for the viewer some information about the Curies' research. Building upon Becquerel's recent discovery that uranium salts emit spontaneous radiation, Marie had realized that the uraniumrich ore she was studying, pitchblende, was more radioactive than uranium itself. Therefore, it must contain at least one other, even more radioactive, element. Crushing the ore, boiling it and removing all known elements: it is by this physically demanding and timeconsuming process that the Curies isolated the new elements.

After years of effort, Marie's announcement of their discoveries on radioactivity (a term she introduced) and of the identification of not one but two new elements, polonium and radium, marked her rise to fame. In the early 1900s, the discovery that radioactivity could shrink tumours caused a wave of optimism. The realization that it could also cause tumours was still to come. At this point in the story, we are taken to the first flash-forward of the film: in 1957 , a boy with cancer is treated with radiation in Cleveland, $\mathrm{OH}$, USA.

In 1903, the Curies were awarded the Nobel Prize in Physics, shared with Becquerel. The nominating committee had initially considered only Pierre and Becquerel, but when Pierre caught wind of this he insisted Marie was included. In the film, he is portrayed going to Stockholm alone and coming back to a bitter row because Marie felt that Pierre alone was getting recognition. In reality, neither of them went to Stockholm in 1903 on account of their teaching obligations. They went two years later, together.

In his Nobel lecture, Pierre asked a question in which Satrapi saw a forewarning of things to come: "will knowledge be harmful for humankind?" The next thing we are shown is the Enola Gay dropping the atomic bomb on Hiroshima. Later on we get a glimpse of an atomic village in Nevada full of plastic people melting away in an atomic test in 1961. Towards the end of the film, images from Chernobyl fill the screen. "This is a biography of radioactivity, not only of Marie Curie," clarified Satrapi in the Q\&A that followed the screening of the UK premiere.

Implying that Marie and Pierre Curie are somehow responsible for later atomic disasters is, in my opinion, shameful. Indeed, Pierre's quotation is removed from its context: the original paragraph from his Nobel speech ends by saying "I am one of those who believe that mankind will derive more good than harm from the new discoveries."
Pierre tragically died in 1906 in an accident. A couple of years later Marie fell in love with a married former collaborator, Paul Langevin. As newspapers got hold of the story, a media storm was unleashed, with the scandal intertwined with xenophobia (she was Polish) and rumours that she was Jewish.

The turmoil almost put off the Nobel committee from awarding her a second prize, this time for Chemistry, which she received in 1911. They suggested she should not go to Stockholm until things settled. With characteristic fierceness, she refused to have judgment of her scientific work mixed up with her private life and went anyway.

During World War I, it was Marie who pushed for the establishment of mobile X-ray machines that could be taken to the battlefield. She drove one of the mobile units herself, together with her teenage daughter Irène.

In the last scenes of the film, as she is dying, Marie sees the future victims of radioactivity lying in their hospital beds. In the closing remarks, the beneficial applications of radioactivity are highlighted, and the film ends on the picture of the Solvay conference, in which finally we see Marie surrounded by scientists who are not Pierre Curie or Paul Langevin, revealing she was not the isolated character the film suggests, but an active member of the scientific community of her time.

What the film lacks, I find, is context. It jumps to Marie's formative years of struggle and sacrifice as a female, and foreign, student in Paris. Her prior studies in a clandestine university in Poland, where women had no official access to higher education, and her years working as a governess to support her studies in France would have also been worth a mention. Not all stories need to start from the beginning, but if this story wants to go beyond a love story — which it must - it should acknowledge that there was a Marie before she became a Curie.

Although I commend the film's effort to show the human side of Marie and details of her daily life, the discovery of radium and polonium was portrayed too quickly, almost giving the impression that she had it all figured out from the start. Her perseverance in pursuing her research is the main reason why Marie Curie is an icon, and the discovery of the 


\section{BOOKS \& ARTS}

new elements is a fascinating story in its own right. It would have deserved more space in a "biography of radioactivity."

On the positive side, the film is visually powerful, and it is fascinating to see what the Curies' lab and daily work would have looked like. The choice of electronic music for the soundtrack is fitting in that their research on radioactivity was ahead of their time.
Impactful visionary scenes punctuate the film and show the influence of the graphic novel it is adapted from (incidentally, this was Satrapi's medium of choice for her own biography).

The insertion of nightmarish scenes depicting nuclear disasters does not make the film a history of radioactivity. It implies that the Curies' fundamental research is the root cause of later horrors. Satrapi said that giving this impression was not the intention, but she felt as though Marie must have had inklings of the things that would come. Nuclear fission was discovered four years after Marie's death. Even the most brilliant mind could not have foreseen that.

Reviewed by Giulia Pacchioni

e-mail:nrmaterials@nature.com https://oi.org/10.1038/s41578-020-0224-y 